\title{
Influence of Deposition Time on Structural and Optical Properties of Chemically Deposited SnS Thin Films
}

\author{
T.H. Patel* \\ V.P. \& R.P.T.P. Science College, Sardar Patel University, Vallabh Vidyanagar Pin: 388120 Gujarat, India
}

\begin{abstract}
Using chemical bath deposition (CBD) technique SnS thin films have been deposited at room temperature with different deposition times. The deposited films have been investigated through $\mathrm{X}$ - ray diffraction measurements to determine structural properties. The deposited SnS films found amorphous and polycrystalline with an orthorhombic herzenbergite structure. The grain size found to increase with deposition time. The surface morphology of the films has been examined using scanning electron microscopy (SEM). The chemical compositions of the films have been determined using energy dispersive analysis of $x$-rays (EDAX). The optical absorption spectra of the films in the wavelength range of 200-1200 $\mathrm{nm}$ have been investigated to determine the optical band gap and types of transitions involved in the absorption process. The direct allowed transitions found to be dominant and the corresponding band gap found to decrease with increase in deposition time. In order to evaluate the electrical parameters, thermoelectric power measurements have been performed. The films exhibited p-type electrical conductivity. A systematic study on the influence of deposition time on the properties of $\mathrm{SnS}$ thin films deposited by $\mathrm{CBD}$ at room temperature has been reported.
\end{abstract}

Keywords: Band gap, chemical bath deposition, lattice parameters, optical absorption, tin sulfide electron microscopy, X-ray diffractogram,

\section{INTRODUCTION}

The search for thin film materials for solar energy conversion and other related applications has been recently identified. Many efforts have been geared towards using metal chalcogenides as this class of materials had shown somewhat superior performance when compared to others. Among the important binary semiconductors of IV-VI group, the chalcogenides formed with $\mathrm{Sn}$, especially $\mathrm{SnS}$ have attracted considerable attention in recent years. The lattice structure of $\mathrm{SnS}$ is closely related to the black phosphorous structure and can be considered either as a distortion of the $\mathrm{NaCl}$ structure or as a binary analog of the layered arsenic structure. The tin sulfide $(\mathrm{SnS})$ is having orthorhombic crystal structure with eight atoms per unit cell. The cation $(\mathrm{Sn})$ and anion $(\mathrm{S})$ atoms form double layers made up of two planes of zigzag cation-anion chains perpendicular to the longest crystallographic axis. The double layers are stacked to each other through a weak van der Wall's interaction whereas a relatively strong covalent bonding between the cation and anion atoms exists within the layers [1]. The compound $\mathrm{SnS}$ is a semiconductor with a band gap of $1.3 \mathrm{eV}$ [2] and hence with the potential to become a versatile solar energy material. The high conversion efficiency obtainable from it in photovoltaic devices, according to Prince-Loferski diagrams and its acceptability from the point of view of cost, availability, toxicity and stability ascribe to $\mathrm{SnS}$ a unique position among the metal sulfides. The narrow band gap and the interesting structural properties of SnS satisfy most of the criterion to make them potential candidate in

*Address correspondence to this author at the V.P. \& R.P.T.P. Science College, Sardar Patel University, Vallabh Vidyanagar Pin: 388120 Gujarat, India; Tel: +91 2692230011 235207; Fax: +91 2692 235207;

E-mail: pateltarunh@yahoo.com photoelectrochemical solar cells, as solar absorbers in thin film solar cells, near infrared detectors, as photovoltaic materials and in other optoelectronic systems. The SnS films show both direct and indirect absorptions at room temperature. It exhibits p-type conduction and high absorption coefficient of the order of $10^{4}$ to $10^{5} \mathrm{~cm}^{-1}$ [3]. The most extensively studied thin film solar cells are based on $\mathrm{CdTe}$ and $\mathrm{Cu}(\mathrm{In}, \mathrm{Ga}) \mathrm{Se}_{2}$ (CIGS). However, there are concerns existing with respect to the use of $\mathrm{Cd}$ and $\mathrm{In}$ in this type of applications due to cost, toxicity, abundance and environmental issues. $\mathrm{SnS}$ is one of the promising materials for low cost thin film solar cell technology, due to its optimum energy gap, a high fundamental absorption coefficient, non toxicity and abundance.

For the deposition of thin films of $\mathrm{SnS}$ various methods like spray pyrolysis [4-10], electrodeposition [11-17], chemical vapor deposition [18-20], magnetron sputtering [21], successive ionic layer adsorption and reaction (SILAR) [22], vacuum evaporation [23-34], brush plating [35-36], microwave assisted chemical deposition [37] and chemical bath deposition (CBD) [38-53] have been employed. Among these methods CBD is relatively simple, more rapid and inexpensive method suitable for deposition on large substrates irrespective of the shape and morphology of substrates nearly at room temperature. Mainly, it is a technique for thin film deposition on a substrate from a diluted solution comprising of a source of metal, hydroxide and sulfide or selenide ions. In CBD control of reaction rate and $\mathrm{pH}$ of the bath is very necessary to deposit a good quality film. For this, use of appropriate buffer solutions in the bath has been seen many times [38-39]. Most of the CBD deposited SnS films used stannous chloride salt as a tin ion source and thioacetamide [38-39] or sodium thiosulphate pentahydrate $[42,47]$ or sodium sulphate [54] as a sulphur 
ion source in the bath. To slowdown the immediate precipitation of the precursors in the bath buffer solutions are used. At the same time, increase in temperature increases the rate of reaction in the bath leading to an early deficit of the ions in the bath with may lead to a reverse reaction exhibiting pilling off of the deposited film. At low temperature the rate of reaction becomes low as compared to that at higher temperature which can be monitored and then optimized for better deposition of the film. Hence low temperature deposition of the film is interesting and challenging. Recently, the effect of deposition time on the properties of SnS thin films deposited by CBD using a buffer solution (ammonia/ammonium chloride) at $60{ }^{\circ} \mathrm{C}$ has been reported [38]. Such study on $\mathrm{SnS}$ thin films deposited at room temperature by $\mathrm{CBD}$ has not been found in literature survey. The temperature of the bath strongly influence the reaction mechanism and hence the formation of the film. Also at room temperature, the particle do not have enough kinetic energy and hence less probability to reach the substrate with a greater momentum to form a quick film. Under such condition the formation of $\mathrm{SnS}$ from the anion and cations preferably governs by the chemistry of the reactants only. In this context, a systematic study on the effect of deposition time on the structural and optical properties of $\mathrm{SnS}$ thin films at room temperature has been reported in the present work.

\section{EXPERIMENTAL}

\section{Deposition of SnS Films}

For the synthesis of $\mathrm{SnS}$ thin films using $\mathrm{CBD}, \mathrm{AR}$ grade $\mathrm{SnCl}_{2} 2 \mathrm{H}_{2} \mathrm{O}$ and thioacetamide (TA) were used as $\mathrm{Sn}$ and $\mathrm{S}$ source respectively. The deposition bath was prepared first by mixing the $5 \mathrm{ml}$ of $1 \mathrm{M} \mathrm{SnCl}_{2} 2 \mathrm{H}_{2} \mathrm{O}$ with $10 \mathrm{ml}$ of $3.75 \mathrm{M}$ triethanolamine (TEA) (as supplied diluted to 50\%) under a vigorous stirring. $2 \mathrm{ml} \mathrm{NH}_{3}$ was added drop-wise with constant stirring followed by addition of $5 \mathrm{ml}$ of $1 \mathrm{M}$ TA. Finally distilled water added to make a total of $100 \mathrm{ml}$. The $\mathrm{pH}$ of the bath was kept 9.70 using ammonia. The solution was transferred to another thoroughly cleaned glass beaker with well cleaned amorphous glass substrate $(76 \mathrm{~mm} \times 26 \mathrm{~mm}$ $\mathrm{x} 1 \mathrm{~mm}$ ) placed inclined and rested on beaker wall. Before deposition process glass substrates were thoroughly cleaned using detergent, chromic acid and isopropyl alcohol in a systematic manner. The films were deposited at room temperature $\left(27{ }^{0} \mathrm{C}\right)$ with deposition time of $24 \mathrm{~h}, 48 \mathrm{~h}$ and $72 \mathrm{~h}$. Each deposited film was sprayed with distilled water immediately after it was taken out of the beaker, allowed to dry and then kept in a desiccator to avoid any unwanted atmospheric effects.

\section{Characterization of $\mathrm{SnS}$ thin Films}

The X- ray diffractograms of the films were obtained using Philips Xpert MPD diffractometer employing $\mathrm{CuK} \alpha$ radiation with $\lambda=0.15406 \mathrm{~nm}$ in $2 \theta$ range from $20^{\circ}$ to $70^{\circ}$. For surface morphology scanning electron microscopy (SEM) pictures were taken using computer controlled digital scanning electron microscope model Philips XL30 ESEM. The chemical compositions of the films were determined from the energy dispersive analysis of X-rays (EDAX) spectra obtained using the system attached with Philips XL30 ESEM. For the optical analysis, the optical spectra of the films were obtained using Perkin Elmer Lambda 19 UV-
VIS-NIR spectrometer in the wavelength range $200 \mathrm{~nm}$ to $1200 \mathrm{~nm}$. The Hall effect measurements were attempted on the films using Lakeshore 7504 Hall measurement set up system at room temperature. The thermoelectric power (TEP) measurements were carried out using the set-up available at and developed by Physics Department of S.P. University, Vallabh Vidyanagar, India.

\section{RESULTS AND DISCUSSION}

\section{Mechanism of SnS Thin Film Deposition in CBD}

Chemical bath deposition (CBD) refers to the deposition of films on a solid substrate from reaction occurring in a solution, almost always aqueous. Although CBD has been in use for long time involving quite simple reactions, the mechanism of the CBD process is often unclear. There are several mechanisms of CBD which can be divided into four fundamentally different types as; the simple ion-by-ion mechanism, simple cluster (hydroxide) mechanism, complex decomposition ion-by-ion mechanism and complex decomposition cluster mechanism as long as formation of metal chalcogenide films are concerned [44]. The first two mechanisms involve free chalcogen ion while the last two do not involve formation of free chalcogen ion. In simple ionby-ion mechanism, first ions diffuse over the substrate which serve as a catalyst and facilitate the nucleation. The nucleation grows as a result of absorption of ions in the solution and nucleation of new crystals occurs. At further stage the crystals bonds with one another by the van der Walls forces forming a film. In simple cluster mechanism, hydroxide colloidal particles diffuse to substrate and adhere to it. These hydroxide colloidal particles adsorbed to substrate react with free ions in the solution resulting in displacement of hydroxide by the free ions. Such displacement reaction can occur both on the substrate and in the solution and continues until most of the hydroxide converts into sulfide. The primary particles occurring by reaction adhere to each other to make up an aggregated film on the substrate and other nonadsorbed particles also aggregate and precipitate out of the solution. In last two complex decomposition mechanisms, the complex (Sn-S-L, where $\mathrm{L}$ is ligand or part of the $\mathrm{S}$ forming species) decomposes to $\mathrm{SnS}$ on the substrate and to a greater or lesser extent also homogeneously in the solution. The $\mathrm{SnS}$ nuclei formed grow by adsorption and decomposition of more complex species until a film of aggregated crystal is formed in a similar manner as for the first two mechanisms.

While using CBD method, to deposit a good quality thin film on the substrate it is very important and essential that the reaction process in the bath leading to film formation must be sufficient slow enough. In the deposition process of $\mathrm{SnS}$ films when TEA was not used, the precipitation of solid elements like $\left[\mathrm{Sn}(\mathrm{OH})_{2}\right]$ occurs very rapidly in the solution and a proper film was not obtained on the substrate. In order to form a good quality film on the substrate, formation of such elements should be prevented and the rate of reaction must also be slowed down. To ensure these conditions TEA was used in the synthesis process as it acts as a good complexing agent with metal ions. The basic chemical reaction that leads to formation of $\mathrm{SnS}$ thin films is considered as follows [45]. 
$[\mathrm{Sn}(\mathrm{TEA})]^{2+}+\mathrm{CH}_{3} \mathrm{CSNH}_{2}+2 \mathrm{OH}-\mathrm{SnS}+\mathrm{TEA}+$ $\mathrm{CH}_{3} \mathrm{CONH}_{2}+\mathrm{H}_{2} \mathrm{O}$

The $\mathrm{Sn}^{2+}$ ion complexes with TEA initially to form $[\mathrm{Sn}(\mathrm{TEA})]^{2+}$ during the deposition preventing the rapid formation of solid materials like $\left[\mathrm{Sn}(\mathrm{OH})_{2}\right]$ and later this complex decomposes and releases $\mathrm{Sn}^{2+}$ ions to make bonds with $\mathrm{S}^{2-}$ ion present in the solution to form $\mathrm{SnS}$.

During the deposition time the color of the solution in the bath was observed to change from initially milky white to light yellowish brown in couple of hours then to chocolate brown and with further increase in time to deep brown. The films obtained after deposition time of $24 \mathrm{~h}$ were found to be light brown with yellowish transmission in daylight and reflecting multicolor whereas the films obtained after deposition time of $48 \mathrm{~h}$ and $72 \mathrm{~h}$ were found to be deep brown-blackish with deep reddish transmission and reflecting like mirror. The change in appearing color of the film is mainly attributed to the increase in thickness of the film with the increase in deposition time since $\mathrm{Sn} / \mathrm{S}$ ratio is not much affected in the films as per the EDAX results. The SnS films of deep brown or chocolate color have been reported recently $[10,39,55]$. Very recently, color dependence of the SnS film on the film thickness has been reported revealing that color of $\mathrm{SnS}$ film changes from pale yellow to brown with increase in film thickness [56]. It should be noted that films deposited on the lower side of the substrate facing the bottom of the beaker only found well adherent and taken for studies while that on the upper side found to washed off easily with spray of distilled water.

\section{Structural Analysis}

The x-ray diffraction patterns of the films deposited at different deposition times of $24 \mathrm{~h}, 48 \mathrm{~h}$ and $72 \mathrm{~h}$ at room temperature are shown in Fig. (1). For all films, the observed peaks have been analyzed and indexed using standard pattern for the mineral herzenbergite with orthorhombic structured SnS (JCPDS PDF Card \# 39-0354). The analysis of the XRD pattern of film deposited after $24 \mathrm{~h}$ indicates formation of a poorly crystalline film. Except for compounds that are commonly amorphous, CBD semiconductor films are rarely truly amorphous. Most of these films are classified as "amorphous" or "poorly crystalline" either on the basis of lake of any XRD peak or because the peak(s) are very broad [44] as it happens in this case also. The peaks observed in Fig. (1) at $2 \theta$ values of $26.34^{\circ}, 31.88^{\circ}$ and $42.80^{\circ}$ were found to match with reflections from (120), (040) and (210) crystallographic planes of orthorhombic phase of $\mathrm{SnS}$ respectively. The peak seen at $26.34^{\circ}$ is found also to contributing through reflections of maximum intensity from (110) plane of mineral cassiterite $\left(\mathrm{SnO}_{2}\right)$ (JCPDS PDF Card \# 41-1445) from the glass substrate as observed earlier too [43].

The XRD patterns of films deposited after $48 \mathrm{~h}$ and $72 \mathrm{~h}$ shown in Fig. (1) exhibits sharp peaks at $2 \theta$ values of $31.48^{0}$ and $31.42^{0}$ respectively corresponding to (111) planes of orthorhombic structured SnS ( PDF Card \# 39-0354). There are some less intense peaks revealing good quality polycrystalline films with preferred orientation from (111) plane. In the XRD pattern of film with deposition time of $48 \mathrm{~h}$, a peak at $2 \theta$ values of $35.06^{\circ}$ and in the XRD pattern of film with deposition time of $72 \mathrm{~h}$ peak at $2 \theta$ values of $34.86^{\circ}$ are identifies as originating from (101) plane of Sn (PDF\#18-1380). It should be noted that peaks corresponding to other phases of $\mathrm{SnS}\left(\mathrm{SnS}_{2}\right.$ or $\left.\mathrm{Sn}_{2} \mathrm{~S}_{3}\right)$ have not been found during the XRD analysis.

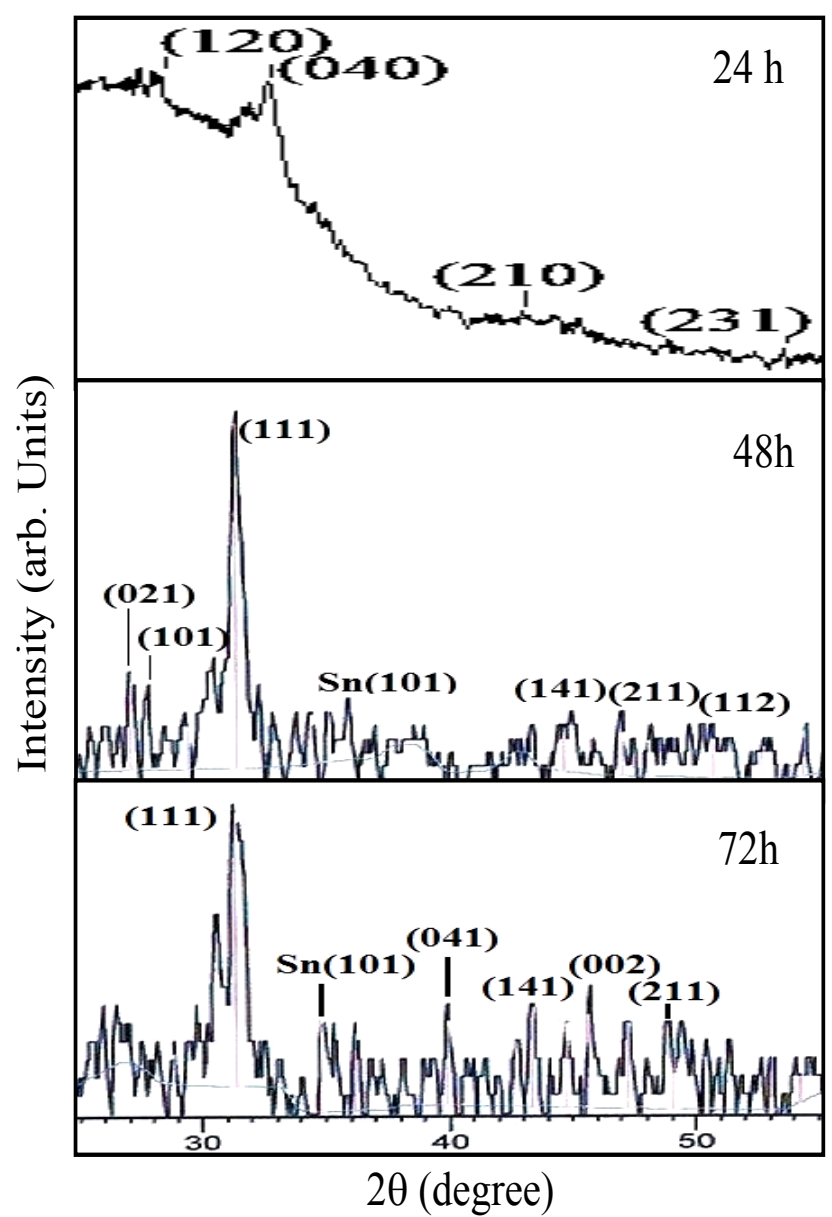

Fig. (1). XRD spectra of $\mathrm{SnS}$ films deposited using CBD with different deposition times.

The lattice parameters of the deposited films have been calculated from the observed values of $2 \theta^{\circ}$ and using $d$ values (interplaner spacing) for the orthorhombic structure, which is given by [57]:

$\frac{1}{d_{h k l}^{2}}=\frac{h^{2}}{a^{2}}+\frac{k^{2}}{b^{2}}+\frac{l^{2}}{c^{2}}$

where $(h k l)$ are the Miller Indices of the plane concerned and $a, b$ and $c$ are lattice parameters. The values of lattice parameters so obtained are shown in Table $\mathbf{1}$. The values of the lattice parameters have been found in good agreement when compared with the standard values taken from JCPDS Card \# 39-0354. The crystallite or grain sizes were estimated using the Scherrer's formula [57]:

$D=\frac{0.9 \lambda}{\beta_{c} \cos \theta}$

where $D$ is the crystallite size, $\lambda$ is the wavelength of the $\mathrm{CuK} \alpha$ radiation, $\beta_{c}$ is the experimentally observed diffraction peak width at half maximum intensity (FWHM) and $\boldsymbol{\theta}$ is the 
Bragg angle. The values of the crystallite size determined using above relation are $13.06 \mathrm{~nm}, 26.9 \mathrm{~nm}$ and $27.05 \mathrm{~nm}$ for the films with deposition time of $24 \mathrm{~h}, 48 \mathrm{~h}$ and $72 \mathrm{~h}$ respectively. When compared to XRD patterns of bulk SnS, the XRD patterns of the deposited films show the broadening of the peaks. Such effects are mainly arising due to small crystalline size and strain. Both crystalline size and strain effects are interconnected in the line broadening of the peaks which makes it difficult to separate. Williamson-Hall technique [58] is one of the many methods for the evaluation and separation of size and strain parameters from the occurring line broadening. In this method which is adopted in present work, grain size $D$ and strain $\varepsilon$ are related as

$\frac{\beta_{c} \cos \theta}{\lambda}=\frac{1}{D}+\varepsilon\left(\frac{\sin \theta}{\lambda}\right)$

where $\beta_{c}$ is the instrumental effect corrected full width at half maximum of the peak measured, $\theta$ is the diffraction angle and $\lambda$ is the wavelength of X-ray. The slope of the plot between $\beta_{\mathrm{c}} \cos \theta / \lambda$ and $\sin \theta / \lambda$ (Williamson - Hall plot) gives micro strain $\varepsilon$ and the inverse of intercept on y axis gives average grain size value. The variation of grain size and strain of $\mathrm{SnS}$ films deposited at room temperature at different deposition time are shown in Fig. (2). The results of the Williamson -Hall plots shown in Table $\mathbf{1}$ indicates that grain size increased from $12.65 \mathrm{~nm}$ to $28.57 \mathrm{~nm}$ as the deposition time increased from $24 \mathrm{~h}$ to $72 \mathrm{~h}$. These values are in good agreement with those obtained from Scherrer formula as shown in Table 1. It is obvious to expect that with increase in deposition more ions released from the reaction contribute to the film formation process leading to an increase in grain size until deficit of either Sn or S ion occurs in the bath solution. Also, with increase in deposition time from $24 \mathrm{~h}$ to $42 \mathrm{~h}$ strain value decreased from $43 \times 10^{-4}$ to 3.6 $\times 10^{-4}$. Similar behavior has been observed on $\mathrm{SnS}$ films deposited with spray pyrolysis at increasing substrate temperature [5]. However, with further increase in deposition time to $72 \mathrm{~h}$ strain value found to increase to $28 \times 10^{-4}$ but still decreased from that for film with deposition time of $24 \mathrm{~h}$. This may seems to be plausible due to sufficient time available for growth of defects as the films remains in the bath for a longer time.

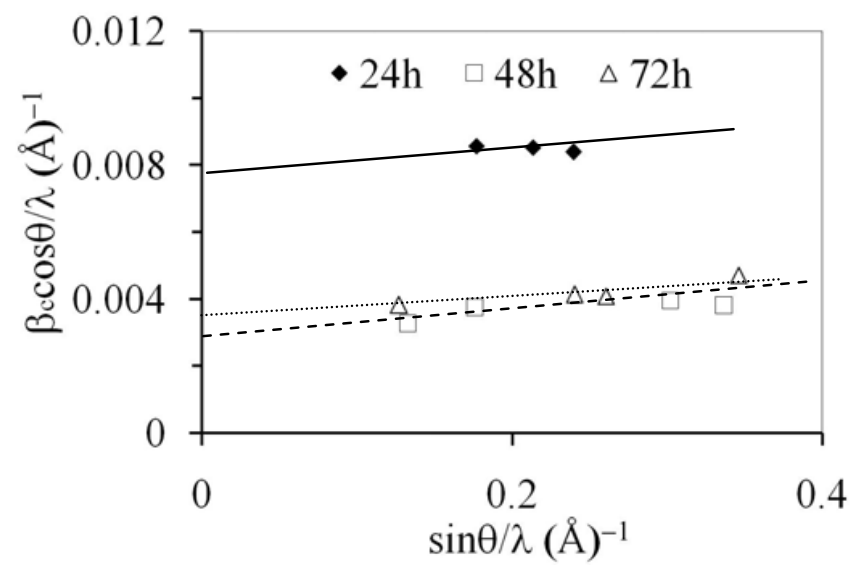

Fig. (2). Williamson-Hall Plots of $\mathrm{SnS}$ films with different deposition times.

\section{Surface Morphology}

The surface morphology of the films deposited at room temperature with different deposition times are shown in Fig. (3). The SEM images show homogeneous surfaces of the films free from any pinhole or cracks with presence of large spherical crystallites surrounded with small crystallites. The

Table 1. Results of XRD Analysis of SnS Films Deposited with Different Deposition Times

\begin{tabular}{|c|c|c|c|c|c|c|}
\hline \multirow{2}{*}{$\begin{array}{c}\text { Dep. } \\
\text { Time } \\
\text { (h) }\end{array}$} & \multicolumn{3}{|c|}{ Lattice Parameter } & \multicolumn{2}{c|}{ Grain Size } & \multirow{2}{*}{$\begin{array}{c}\text { Strain } \\
\text { x 10 }\end{array}$} \\
\cline { 2 - 6 } & $\boldsymbol{a}$ & $\boldsymbol{b}$ & $\boldsymbol{c}$ & $\begin{array}{c}\text { Sherrer } \\
\text { Formula }\end{array}$ & W-H Plot & \\
\hline \hline 24 & 4.38 & 11.20 & 3.99 & 13.06 & 12.65 & 43 \\
\hline 48 & 4.28 & 11.29 & 3.90 & 26.9 & 26.31 & 3.6 \\
\hline 72 & 4.32 & 11.13 & 3.97 & 27.05 & 28.57 & 28 \\
\hline & $4.33^{\mathrm{a}}$ & $11.19^{\mathrm{a}}$ & $3.98^{\mathrm{a}}$ & & & \\
\hline
\end{tabular}

SEM images indicate that with increase in deposition time the number of crystallites increases leading to formation of more homogeneous film. The presence of more number of small grains as compared to larger ones can be attributed due to deposition at room temperature at which ions in the bath generally do not posses enough mobility to form a grain with larger size. The Fig. (3c) is the SEM image of the film deposited after 72 hour. In CBD, after a sufficient time when reaction of formation of $\mathrm{SnS}$ from the respective ions in the bath is saturated the reverse reaction starts which leads to pilling off of the films from the substrate. This effect can be seen just in its initial state to occur in Fig. (3c) in some directions.

\section{EDAX Analysis}

Fig. (4) shows the EDAX spectrum of the film with deposition time of $72 \mathrm{~h}$. The EDAX analysis of the films with deposition time of $24 \mathrm{~h}, 48 \mathrm{~h}$ and $72 \mathrm{~h}$ exhibited atomic ratio of $\mathrm{Sn} / \mathrm{S}$ of $\sim 0.99,1.19$ and 1.18 respectively. This has been indicating that deposited films are almost stochiometric. It is evident that films with deposition time of $48 \mathrm{~h}$ and $72 \mathrm{~h}$ has presence of small excess amount of tin. This may be due to the fact that at longer deposition time the release of $\mathrm{Sn}$ ion is not counterbalanced by availability of $\mathrm{S}$ ions in the bath as concentration of $\mathrm{S}$ ions in the bath had been utilized fully. The results of XRD analysis of the corresponding films justify the presence of $\mathrm{Sn}$. The $\mathrm{Na}, \mathrm{Mg}, \mathrm{Si}, \mathrm{O}$ and $\mathrm{Ca}$ elemental peaks have resulted due to the elements in glass substrates and distilled water.

\section{Optical Analysis}

The optical absorption technique was employed to determine the values of band gap and type of optical transitions involved in the absorption process in the films. The absorption spectra of the films obtained in the 
wavelength range of 200-1200 nm are shown in Fig. (5). The absorption edges have been found broad and pronounced around $800 \mathrm{~nm}$ for film with deposition time of $24 \mathrm{~h}$ and around $850 \mathrm{~nm}$ for films with that of $48 \mathrm{~h}$ and $72 \mathrm{~h}$. It can be seen from the Fig. (5) that absorption edge tends to be sharpening as the deposition time of the film increases. This can be attributed to the increase in thickness of the films with increase in deposition time.

The optical band gaps $E_{g}$ of the films were evaluated using the relation [59]:

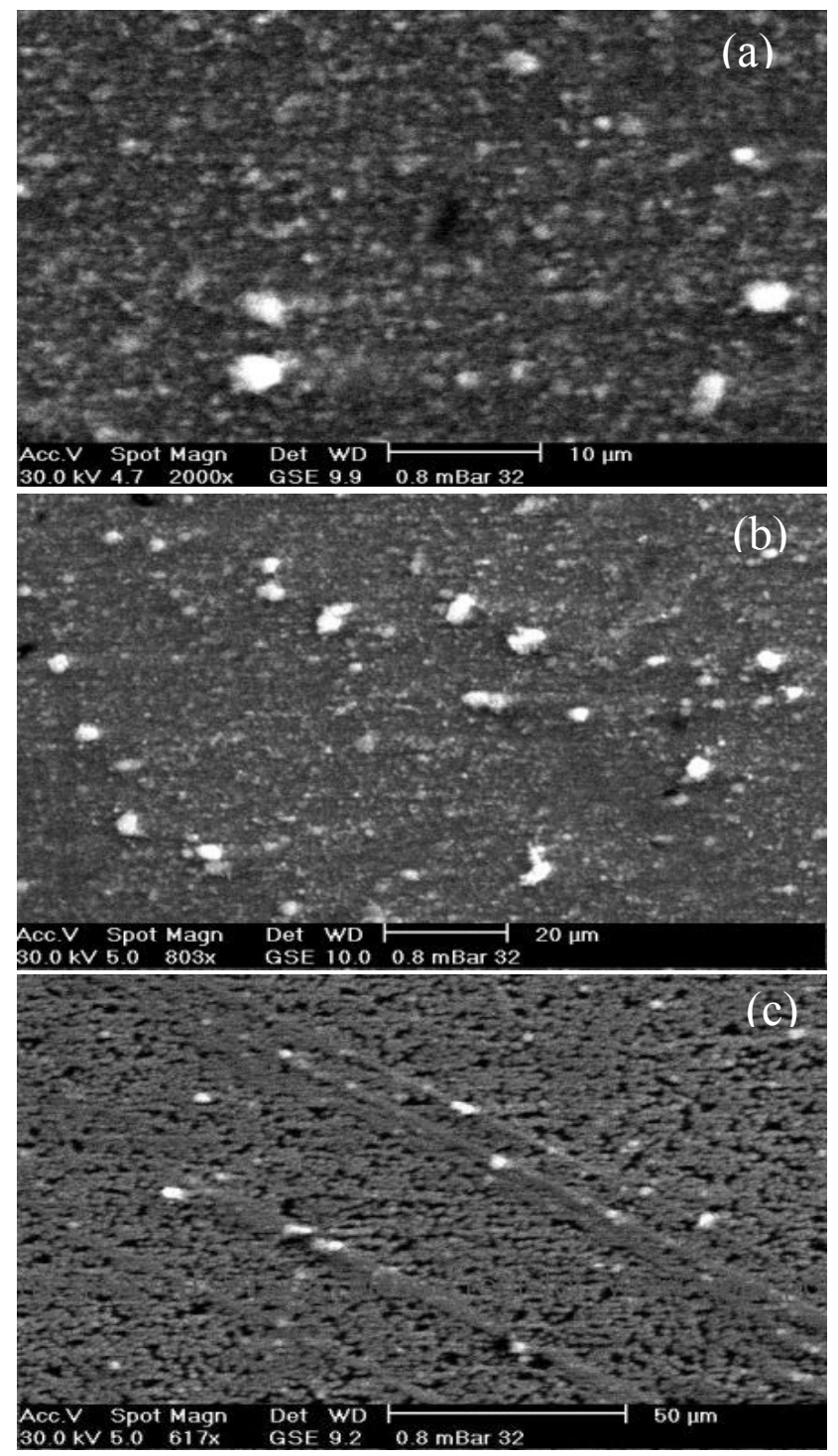

Fig. (3). SEM images of SnS films deposited by CBD at deposition time of (a) $24 \mathrm{~h} \mathrm{(b)} 48 \mathrm{~h}$ and (c) $72 \mathrm{~h}$.

$\alpha h v=A\left(h v-E_{g}\right)^{n}$

where $A$ is the parameter that depends on the transition probability, $\alpha$ is the absorption coefficient and $n$ is the index that has value equal to $1 / 2$ for the direct allowed transitions, 2 for the indirect allowed transitions, $3 / 2$ for direct forbidden transitions and 3 for indirect forbidden transitions. The $\mathrm{SnS}$ thin films prepared by CBD has exhibited both direct $[10,15$, $38-39,41-42,47-48,50-51]$ as well as indirect [11,38-
$39,45,49,51]$ transitions. However to investigate the types of optical transitions involved with the value of corresponding optical band gap, the spectral variations of $(\alpha h v)^{1 / 2},(\alpha h v)^{2}$, $(\alpha h v)^{2 / 3}$ and $(\alpha h v)^{1 / 3}$ were plotted as a function of photon energy hvas shown in Fig. (6) for the SnS films deposited with different deposition times. The value of intercept on the $\mathrm{x}$-axis obtained by extrapolation of the straight-line portion of the curve at $\alpha=0$ has been used to estimate the optical band gap of the corresponding film $[11,13,38$ 40,42,47,49,51]. Also to determine optical band gap many researchers [40] use the Tauc-relation [60] which is consistent with equation (1).

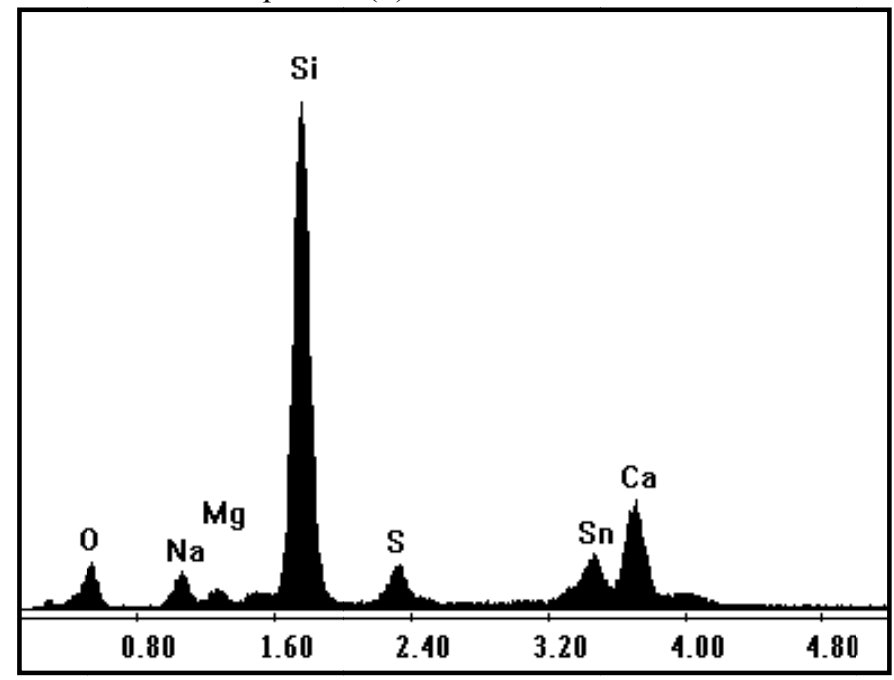

Fig. (4). EDAX spectrum of $\mathrm{SnS}$ film deposited by CBD with deposition time of $72 \mathrm{~h}$.

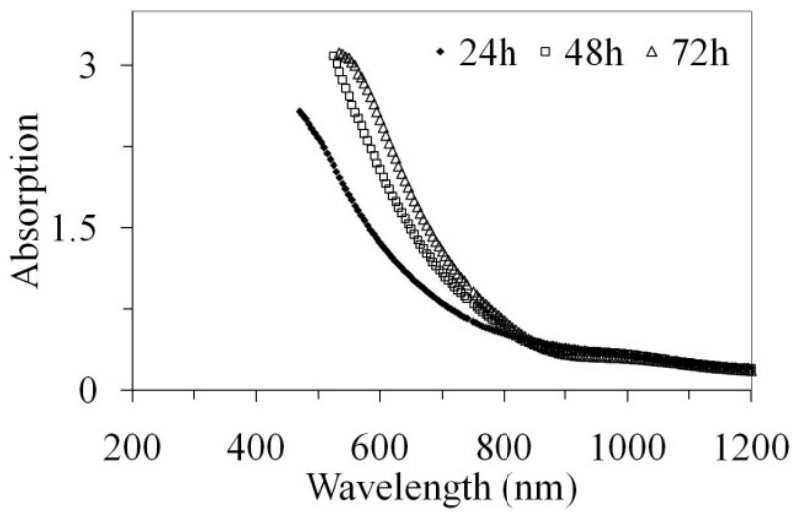

Fig. (5). Optical absorption spectra of $\mathrm{SnS}$ thin films deposited by CBD with different deposition times.

Fig. (6) show that for the deposited films the straight line portion best fits for allowed direct transitions with lesser probability for other transitions. However, the variations of band gap values with deposition time for the deposited films are shown in Fig. (7) for all types of transitions.

The value of indirect allowed band gap found to be not much influenced by deposition time as it decreased fractionally from $1.18 \mathrm{eV}$ to $1.14 \mathrm{eV}$. The values are in the agreement with those reported for $\mathrm{SnS}$ films prepared by CBD [11,38-39,49]. With increase in deposition time the direct forbidden band gap found to decrease from $1.44 \mathrm{eV}$ to $1.32 \mathrm{eV}$. These values are in the range observed earlier [43] 

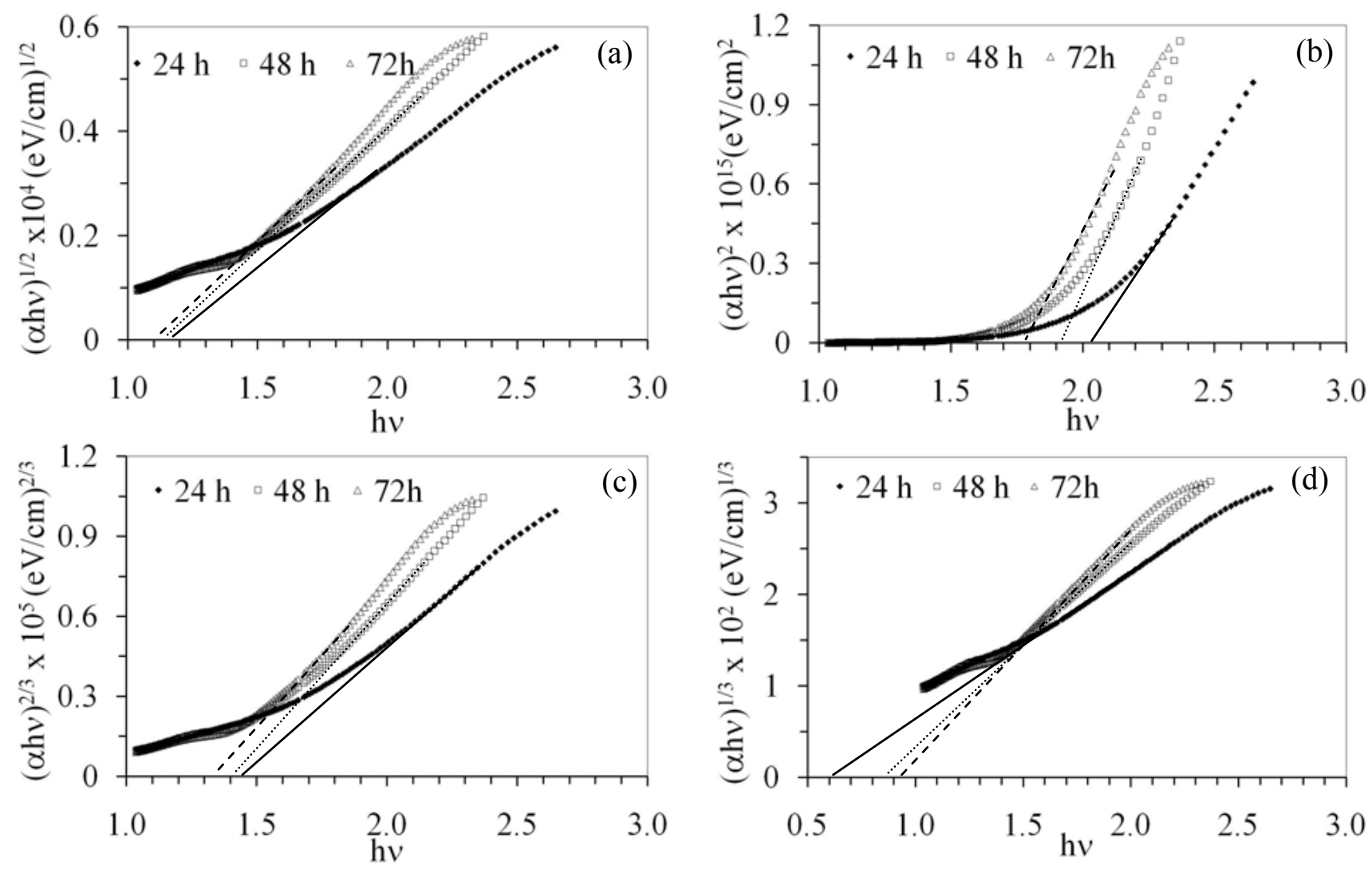

Fig. (6). Spectral variations of (a) $(\alpha h v)^{1 / 2}$, (b) $(\alpha h v)^{2}$, (c) $(\alpha h v)^{2 / 3}$ and (d) $(\alpha h v)^{1 / 3}$ with hv for the SnS films deposited with different deposition times.

but higher than those observed by other researchers $[11,49,52]$ for $\mathrm{SnS}$ films deposited by CBD. The direct forbidden gap of the order of $1.7 \mathrm{eV}$ have been reported for $\mathrm{SnS}$ films prepared by CBD with orthorhombic [49] and zinc blende structures $[11,40,46]$ and also for SnS films prepared by successive ionic layer adsorption and reaction (SILAR) method [61]. The nature of the variations of $(\alpha h v)^{1 / 3}$ as a function of photon energy (hv) as shown in Fig. (6d) indicates that indirect forbidden transitions are less probable in films under investigations. However, indirect forbidden band gap estimated to increase from $0.6 \mathrm{eV}$ to $0.82 \mathrm{eV}$.

The straight line portions of the curves in Fig. (6b) indicate that direct allowed transitions are dominant in the deposited SnS films. The direct band gap decreased from $2.03 \mathrm{eV}$ to $1.79 \mathrm{eV}$ with increase in deposition time. These values are higher than those reported earlier [37,39,41$42,47,50-51]$ but are within the range as observed in $\mathrm{SnS}$ films deposited by CBD [38] at room temperature and $\mathrm{SnS}$ films deposited by thermal evaporation [23-24]. The increase in deposition time improves the crystallnity as well as enhances the film thickness with growth of crystallites of larger size till enough $\mathrm{Sn}$ and $\mathrm{S}$ ions exist in the solution to support the growth mechanism of the film to continue. This mainly affects the optical absorption which eventually affects the optical band gap of the film. The analysis of the XRD patterns of the films showed a better crystallinity and increase in grain size in the films with increase in deposition time. The difference in crystalline structure of the films deposited at room temperature as compared to those mostly prepared at increased temperature may be the reason for higher values of the direct band gap. It should be noted that presence of other phases of tin sulfide i.e. $\mathrm{SnS}_{2}\left(\mathrm{E}_{\mathrm{g}}=2.44\right.$ $\mathrm{eV})$ and $\mathrm{Sn}_{2} \mathrm{~S}_{3}\left(\mathrm{E}_{\mathrm{g}}=2.0 \mathrm{eV}\right)$ is not found in the deposited films. So the decrease in bandgap in these films with increase in deposition time can be attributed mainly to increase in both the grain size and the film thickness with increase in deposition time. For SnS thin films, decrease in band gap with increase in film thickness has been observed several times for films deposited at near room temperature [23-24,38,62]. Use of $\mathrm{SnS}$ thin films with the band gap of the order of $1.7 \mathrm{eV}$ as absorber layer deposited by CBD have been reported recently [43]. The CBD films are often nanocrystalline and the most apparent effect of very small crystal size is the increasing band gap due to size quantization. This effect is quite visible to eye if the band gap is in the visible region of the spectrum. The optical spectroscopy is fast and simple pointer to crystal size, since band gap-size correlations have been made for a number of colloids and films [44]. Also with decrease in deposition time the film thickness also decreases. Since thinner film thickness results in larger transmission in the shorter wavelength, the absorption edge shifts to shorter wavelength, thereby leading to larger bandgap as seen in this study too.

\section{CONCLUSIONS}

Using CBD amorphous and polycrystalline thin films of $\mathrm{SnS}$ are deposited at room temperature without using a buffer solution. The influence of different deposition times on thin films of $\mathrm{SnS}$ deposited using $\mathrm{CBD}$ at room temperature has been studied first time. The XRD analysis of 
the films indicates that films deposited at $24 \mathrm{~h}$ are poorly crystalline (almost amorphous) and the films deposited at $48 \mathrm{~h}$ and $74 \mathrm{~h}$ are polycrystalline with orthorhombic $\mathrm{SnS}$ structure. The XRD analysis indicates that increase in deposition time has improved the crystallinity of the films. The average grain size is found to increase from $\sim 13 \mathrm{~nm}$ to $\sim 28 \mathrm{~nm}$ with increase in deposition time with film color changes form light yellowish brown to deep chocolate drown. The SEM images show that deposited films are

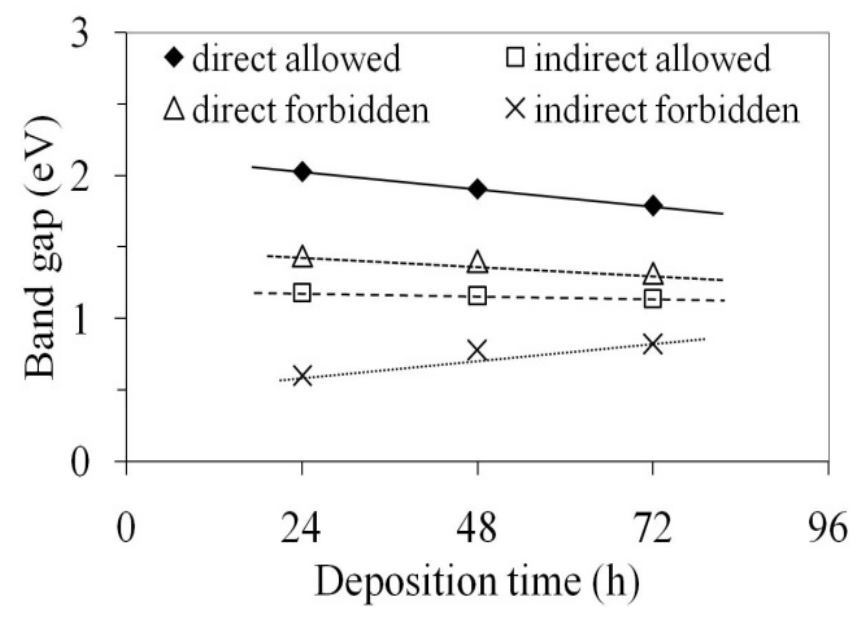

Fig. (7). The variations of band gap with deposition time.

homogeneous and free form any pinholes or cracks with increase in number of crystallites with increase in deposition time. The EDAX report show atomic ration of $\mathrm{Sn} / \mathrm{S}$ in the range from 0.99 to 1.19 suggesting that films deposited are almost stoichiometric. The optical absorption spectra of the films show that direct allowed transitions are dominant in the films. The allowed direct band gap is found to decrease from $2.03 \mathrm{eV}$ to $1.79 \mathrm{eV}$ with increase in deposition time and is mainly attributed to increase in film thickness with increase deposition time. The higher values of the band gap are attributed to small grain size and to the room temperature deposition as other phases of $\mathrm{SnS}$ are not found in the film. The SnS films deposited by CBD with the values of band gap obtained are suitable for absorber layers in solar cells. Work is in progress to investigate in detail the electrical properties of the films. The crystalline and optical property of the films seems to be influenced by the deposition time. The SnS films suitable for photovoltaic structures can be prepared using a cheap, safe simple CBD technique at room temperature.

\section{ACKNOWLEDGEMENTS}

The author is thankful to University Grant Commission (UGC) New Delhi and UGC (WRO) Pune, India for the financial support to this work under the Minor Research Project MRP 47-1340/10. The author is grateful to both, Dr. K.D. Patel, Department of Physics, S.P. University and Dr. K.D. Patel, Chemistry Department, V.P. and R.P.T.P. Science College, Vallabh Vidyanagar, India for their fruitful discussions. Special thanks to SICART Vallabh Vidyanagar for technical support to obtain XRD, SEM, EDAX and Optical spectra.

\section{CONFLICT OF INTEREST}

None declared.

\section{REFERENCES}

[1] Abriksov NKH, Bankia VF, Poretskaya LV, Shelimova LE, Skudnova EV. Semiconducting II-VI, IV-VI and V-VI compounds. Plenum 1969.

[2] Bube RH. Photoconductivity of Solids. New York: Wiley 1960.

[3] Nassary MMJ. Temperature dependence of the electricalconductivity, hall effect and thermoelectric power of SnS single crystals. J Alloys Compd 2005; 398: 21 .

[4] Sajeesh TH, Sudha KC, Sanjeeviraja C, Abe T, Kashiwaba Y, Vijaykumar KP. Ex situ Sn diffusion: a well-suited technique for enhancing the photovoltaic properties of a $\mathrm{SnS}$ absorber layer. J Phys D Appl Phys 2010; 43: 445102.

[5] Jeyaprakash BG, Ashok KR, Kesavan K, Amalarani A. Srtucural and optical characterization of spray deposited SnS thin films. J Amer Sci 2010; 6(3): 22.

[6] Calixto-Rodriguez M, Martinez H, Sanchez-Juarez A, CamposAlvarez J, Tiburcio-Silver A, Calixto ME. Srtucural optical and electrcalproperties of tin sulfide thin films grown by spray pyrolysis. Thin solid films 2009; 517: 2497.

[7] Koteeshwara RN, Ramakrishna RKT. Optical behavior of sprayed SnS films. Mater Res Bull 2006; 41(2): 414.

[8] Ramakrishna RKT, Purandar RP, Miles RW, Datta PK. Investigations on $\mathrm{SnS}$ films deposited by spray pyrolysis. Opt Mat 2001; 17: 295.

[9] Thangaraju B, Kaliannan PP. Spray pyrolytic deposition and characterization of $\mathrm{SnS}$ and $\mathrm{SnS}_{2}$ thin films. J Phys D Appl Phys 2000; 33: 1054.

[10] Koteeshwara RN, Ramakrishna RKT. Growth of polycrystalline SnS films by spray pyrolysis. Thin Solid Films 1998; 325: 4.

[11] Mathews NR, Avellaneda D, Anaya HBM, Campos J, Nair MT, Nair PK. Chemically and electrochemically deposited thin films of tin sulfide for photovoltaic structures. Mater Res Soc Symp Proc 2009; 1165: M08.

[12] Mathews NR. charge transport in a pulse-electrodepositedSnS/Al schottky device. Semicond Sci Technol 2010; 25: 105010.

[13] Yue GH, Wang W, Wang LS, et al. The effect of anneal temperature on physical properties of SnS films. J Alloys Compd $2009 ; 474: 445$.

[14] Subramanian B, Sanjeeviraja C, Jayachandran M. Cathodic electrodeposition and analysis of $\mathrm{SnS}$ films for photoelectrochemical cells. Mat Chem and Phys 2001; 71: 40.

[15] Ichimura M, Takeuchi K, Ono Y, Arai E. Electrochemical deposition of SnS thin films. Thin Solid Films 2000; 98: 361.

[16] Ghazali A, Zainal Z, Hussein M, Kassim M. Cathodic electrodeposition of $\mathrm{SnS}$ in the presence of EDTA in aqueous media. Solar Energy Mater Solar Cells 1998; 55: 237.

[17] Zainal Z, Hussein M, Ghazali A. Cathodic electrodeposition of SnS thin films from aqueous solution. Solar Energy Mater Solar Cells 1996; 40: 347.

[18] Ortiz A, Alonso JC, Garcia M, Toriz J. Tin sulphide films deposited by plasma-enhanced chemical vapour deposition. Semicond Sci Technol 1996; 11: 243.

[19] Engelken R, McCloud H, Lee C, Slayton M, Ghoreishi H. Low temperature chemical precipitation and vapor deposition of $\mathrm{Sn}_{\mathrm{x}} \mathrm{S}$ thin films. J Electrochem Soc 1987; 134(11): 2696.

[20] Stadler A, Schimper HJ, Brendel U, Topa D, Basch A, Dittrich H. Analyzing UV/Vis/NIR spectra with the single-layer modelSputtered SnS thin films I: Space-time dependencies. Thin Solid films 2011; 519: 7951.

[21] Price LS, Parkin IP, Hardy AME, Clark RJH, Hibbert TG, Molloy KC. Atmospheric pressure chemical vapor deposition of tin sulfides $\left(\mathrm{SnS}, \mathrm{Sn}_{2} \mathrm{~S}_{3}\right.$, and $\left.\mathrm{SnS}_{2}\right)$ on glass. Chem Vap Deposition 1998; 4(6): 222.

[22] Ghosh B, Das M, Banerjee P, Das S. Fabrication of SnS thin films by the successive ionic layer adsorption and reaction (SILAR) method. Semicond Sci Technol 2008; 23:125013.

[23] Miles RW, Ogah OE, Zoppi G, Forbes I. Thermally evaporated SnS thin films for solar cells. Thin Solid Films 2009: 517: 4702.

[24] Ogah OE, Zoppi G, Forbes I, Miles RW. Thin films of SnS for use in thin film solar cell devices. Thin Solid Films 2009; 517: 2485. 
[25] Devika M, Koteeswara Reddy N, Patolsky F, Gunashekhar KR. Ohmic contacts to SnS films: selection and estimation of thermal stability. J Appl Phys 2008; 104: 124503-1.

[26] Guo Y, Shi W, Zhang Y, Wang L, Wei G. Influence of substrate temperature on properties of tin sulfide thin films. Proc SPIE 2008; 6984: 6984-1.

[27] Devika M, Koteeswara RN, Sreekantha RD, et al. Synthesis and characterization of nanocrystalline $\mathrm{SnS}$ films grown by thermal evaporation technique. J Electrochem Soc 2008; 155(2): H130.

[28] Koteeswara RN, Hahn YB, Devika M, Sumana HR, Gunasekhar KR. Temperature dependent structural and optical properties of SnS thin films. J Appl Phys 2007; 101: 093522-1.

[29] Koteeswara RN, Ramesh K, Ganesan R, Ramakrishna RKT, Gunasekhar KR, Gopal ESR. Synthesis and characterisation of coevaporated tin sulphide thin films. Appl Phys A 2006; 83(1): 133.

[30] Cifuentes C, Botero M, Romero E, Calderon C, Gordillo G. Optical and structural studies on $\mathrm{SnS}$ films grown by co-evaporation. Braz J Phys 2006; 36(3B): 1046.

[31] Devika M, Ramakrishna RKT, Koteeswara RN, et al. Microstructure dependent physical properties of evaporated tin sulfide films. J Appl Phys 2006; 100: 023518.

[32] Devika M, Koteeswara Reddy N, Ramesh K, et al. The effect of substrate surface on the physical properties of SnS films. Semicond Sci Technol 2006; 21: 1495

[33] El-Nahass MM, Zeyada HM, Aziz MS, El-Ghamaz NA. Optical properties of thermally evaporated SnS films. Opt Mat 2002; 20 : 159.

[34] Noguchi H, Setiyadi A, Tanamura H, Nagatomo T, Omoto O. Characterization of vacuum evaporated tin sulfide film for solar cell materials. Solar Energy Mater Soler Cells 1994; 35: 32.

[35] Subramaniana B, Sanjeeviraja C, Jayachandrana M. Photo electrochemical characteristics of brush plated tin sulfide thin films. Solar Energy Mater Soler Cells 2003; 79: 57.

[36] Jayachandran M, Mohan S, Subramanian B, Sanjeeviraja C, Ganeshan V. Studies on the brush plated SnS thin films. J Mat Sci Lett 2000; 20: 381.

[37] Jeyaparkash BG, Amalarani A, Kesavan K, Mohan S. Characterization of microwave assisted chemically deposited $\mathrm{SnS}$ thin film. Chalcogenide Lett 2009; 6(9): 455.

[38] Guneri E, Ulutas C, Kirmizigul F, Altindemir G, Gode F, Gumus C. Effect of deposition time on structural, electrical and optical properties of SnS thin films deposited by chemical bath deposition. Appl Surf Sci 2010; 257: 1189.

[39] Guneri E, Gode F, Ulutas C, Kirmizigul F, Altindemir G, Gumus C. Properties of p-type $\mathrm{SnS}$ thin films prepared by chemical bath deposition. Chalcogenide Lett 2010; 7(12): 685.

[40] Akkari A, Guasch C, Kamoun-Turki N. Chemically deposited tin sulphide. J Alloys Compd 2010; 490:180.

[41] Wang Y, Reddy Y, Gong H. Large-surface-area nanowall SnS films prepared by chemical bath deposition. J Electrochem Soc 2009; 156(3): H157.

[42] Turan E, Kul M, Aybek AS, Zor M. Structural and optical properties of SnS semiconductor films produced by chemical bath deposition. J Phys D Appl Phys 2009; 42: 245408.
[43] Avellaneda D, Nair MTS, Nair PK. Photovoltaic structures using chemically deposited tin sulfide thin films. Thin Solid Films 2009; 517: 2500 .

[44] Hodes G. Chem Sol Depo of Semicond Films. New York: Marcel Dekker Inc 2003.

[45] Pramanik P, Basu PK, Biswas S. Preparation and characterization of chemically deposited tin(II) sulphide thin films. Thin Solid Films 1987; 150: 269.

[46] Avellaneda D, Nair MTS, Nair PK. Polymorphic tin sulfide thin films of zinc blende and orthorhombic structures by chemical deposition. J Electrochem Soc 2008; 155(7): D517.

[47] Hankare PP, Jadhav AV, Chate PA, Rathod KC, Chavan PA, Ingole SA. Synthesis and characterization of tin sulfide thin films grown by chemical bath deposition technique. J Alloys Compds 2008; 463(1-2): 581

[48] Akkari A, Ben Nasr T, Kamouna N. Structural and optical properties of tin sulphide thin films. AIP Conf Proc 2007; 935: 37.

[49] Avellaneda D, Delgado G, Nair MTS, Nair PK. Structural and chemical transformations in $\mathrm{SnS}$ thin films used in chemically deposited photovoltaic cells. Thin solid Films 2007; 515: 5771.

[50] Xu J, Wei G, Shi W, Chen P, Xue Y. Preparation and characterization of chemically deposited SnS thin films. Proc SPIE 2004; 5774: 254

[51] Tanusevski A. Optical and photoelectric properties of SnS thin films prepared by chemical bath deposition. Semicond Sci Technol 2003; 18: 501

[52] Nair MTS, Lopez MC, Gomez DO, Nair PK. Copper tin sulfide semiconductor thin films produced by heating $\mathrm{SnS}-\mathrm{CuS}$ layers deposited from chemical bath. Semicond Sci Technol 2003; 18 755.

[53] Nair MTS, Nair PK. Simplified chemical deposition technique for good quality SnS thin films. Semicond Sci Technol 1991; 6: 132.

[54] Ristov M, Sinadinovski G, Grozdanov I, Mitreski M. Chemical deposition of tin(II) sulphide thin films. Thin Solid Films 1989; 173: 53 .

[55] Reddy NK, Reddy KTR. Thin Solid Films. In press 2011.

[56] Shuying C, Gavin C. Physical properties of very thin SnS films deposited by thermal evaporation. Thin Solid Films 1998; 325: 4

[57] Cullity BD, Stock SR. Elements of X-ray diffraction. $3^{\text {rd }}$ ed. Englewood Cliffs NJ: Prentice Hall 2001.

[58] Williamson GK, Hall WH. X-ray line broadening from field aluminum and wolfram. Acta Metallurgica 1953; 1: 22.

[59] Pankove JI. Optical processes in semiconductors. New York: Dover Publications Inc 1975.

[60] Tauc J, Abeles F, Eds. Optical properties of solids. Amsterdam: IOP Publishing Ltd 1970.

[61] Gao C, Shen H, Sun L, Huang H, Lu L, Cai H. Preparation of SnS films with zinc blende structure by successive ionic layer adsorption and reaction method. Matt Lett 2010; 64: 2177.

[62] Selim MS, Gouda ME, El-Shaarawy MG, Salema AM, Abd ElGhany WA. Effect of thickness on optical properties of thermally evaporated SnS films. J Appl Sci Res 2011; 7(6): 955 